\title{
Machining Of Composites An Overview
}

\author{
Vijayaraghavan L \\ Professor, Dept. of Mechanical Engineering, IIT Madras, Chennai, India
}

\begin{abstract}
Today's technological progress is due to sophistication in materials. As the technology becomes more and more advanced, the materials used have to be reliable and more efficient in performance. Materials should be light in weight, strong, tough, wear resistant and capable of withstanding extreme operating environments such as high temperature, pressure, cryogenic conditions, high vacuum, highly corrosive and in some cases electric, magnetic or irradiation fields. No individual material is capable of meeting these demands. Thus it is necessary that the material system should preferably be designed for specific end use (tailor-made) necessitating a combination of desired properties. This has resulted in the development of advanced materials and composites form one class of such materials. Composites represent a combination of at least two chemically distinct materials with a distinct interface separating the constituents. These are three kinds of composites: Polymeric matrix (PMC such as FRP), Metal matrix (MMC) and Ceramic matrix (CMC) materials. Their high strength to weight ratio, enhanced resistance to environmental hazards, lower density, high fatigue resistance, wear resistance and related properties has widened the range of application leading to large scale substitution of conventional engineering materials for aerospace to consumergoods.
\end{abstract}

Key words: FRD, Metal Matrix Composites, Particulate Metal Matrix Composites, Ceramic Matrix Composites

\section{INTRODUCTION}

\section{A. Metal Matrix Composites (mmc)}

Metal Matrix MMC's find application in different industries like aerospace (for fuselage of space shuttle orbiter, vertical tail section of advanced fighter planes), automobile engine parts (piston, cylinder liners, brake drums), sports equipments, shipping industry etc.,

Particulate metal matrix composites (PMMC) are of particular interest, since they exhibit higher ductility and lower anisotropy than fiber reinforced MMCs, economically cheaper in both raw materials and fabrication process. Even small additions of reinforcement moderately increase the base alloy strength and stiffness. They also increase the wear resistance but contribute to machining difficulties (due to anisotropic, inhomogeneous and abrasive nature of reinforcement). Mechanical properties such as creep and fatigue are greatly influenced by the condition of the surface. Hence the effect of machining on the type of surface defects, as well as on their distribution, has a major impact on the performance of the machined component.

\section{B. Polymric Matrix Composites (pmc)}

PMC's is material consisting of polymer (resin) matrix combined with a fibrous reinforcing dispersed phase. PMC's are very popular due to their low cost and simple fabrication methods. PMC's were mainly developed for aerospace applications where the reduction of the weight was the principal objective, irrespective of the cost. The scientific efforts in this field were therefore focused to the comprehension and optimization of the structural performances of these materials. PMC's characterized by the following properties such as high tensile strength, high stiffness, high fracture toughness, good abrasion resistance, good puncture resistance, good corrosion resistance and low cost.

\section{Ceramic Matrix Composites (cmc)}

CMC's have been developed to overcome the intrinsic brittleness and lack of reliability of monolithic ceramics, with a view to introduce ceramics in structural parts used in severe environments, such as rocket and jet engines, gas turbines for power plants, heat shields for space vehicles, fusion reactor first wall, aircraft brakes, heat treatment furnaces, etc. It is generally admitted that the use of CMC's in advanced engines will allow an increase of the temperature at which the engine can be operated and eventually the elimination of the cooling fluids, both resulting in an increase of yield. Further, the use of light CMC's in place of heavy superalloys is expected to yield significant weight saving. The desirable characteristics of CMCs include high-temperature stability, high thermalshock resistance, high hardness, high corrosion resistance, light weight, nonmagnetic and nonconductive properties.

\section{CASE STUDY I -GRINDING OF MMCs:}

Although near net shape manufacturing can be done, final finishing process like grinding may still be needed for achieving the final desired dimensions and required surface finish. It is known that, there will be loading for a soft material like Aluminium, but the presence 
of reinforcement enhances the machinability both in terms of surface roughness and lower tendency to clog the wheel [S.Sundaram, 2001]. The mechanism of machining of $\mathrm{SiC}$ reinforcement depends largely on the deformation of the Al matrix during machining [Cheung, 2002]. Conventional $\mathrm{SiC}$ wheels are widely used, since they are economically more viable compared to superabrasive grinding wheels; hence a detailed study on grinding of MMC's with conventional $\mathrm{SiC}$ wheel has been carried out to evaluate wheel performance.

\section{WORKPIECE}

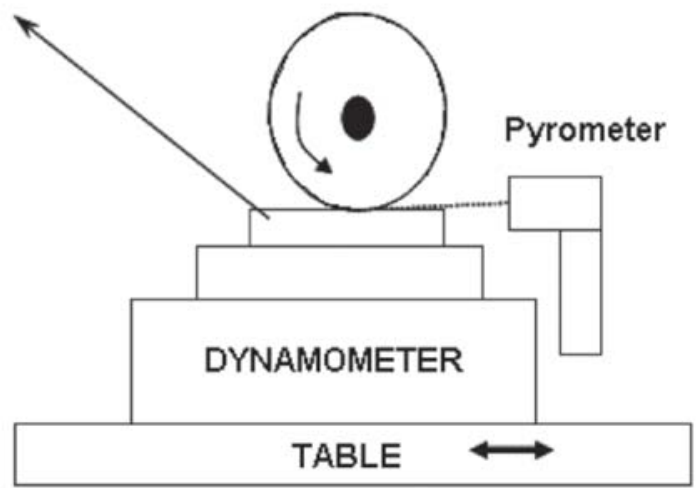

Fig.1 Schematic Diagram of the Experimental Set-up

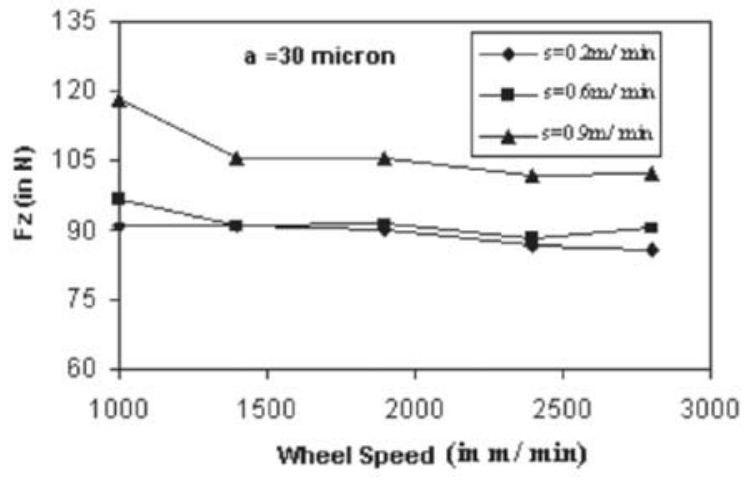

Fig.2 Typical Parametric Influence on Normal Force $\left(F_{z}\right)$ Component

The workpiece was Al 2124 alloy matrix composite reinforced with $\mathrm{SiC}_{\mathrm{p}}(5 \mathrm{~m} / 30 \%)$, manufactured through the Powder Metallurgy (P/M) route. The experiments were conducted by varying the wheel speed (V), feed (s) and depth of grinding (a) and by monitoring the process parameters like force, temperature induced and surface finish. The schematic diagram of the experimental set-up is shown in Fig.1.

Typical observed parametric influence on normal force $\left(F_{z}\right)$ is illustrated in Fig.2. It is seen that with higher table traverse, $F_{z}$ tends to drop down with speed. With low speed range the drop in $\mathrm{F}_{z}$ can be attributed to change from plow dominant grinding to steady grinding. The marginal drop in $F_{2}$ with higher speed could be attributed to thermal softening. Upto moderate feed, the $F_{z}$ component is relatively speed insensitive.

It can be seen that above $1400 \mathrm{~m} / \mathrm{min}$ of wheel speed, a change in trend of variation of temperature occurs. Upto moderate feed, a rise in temperature occurs above $1400 \mathrm{~m} / \mathrm{min}$, while with high feed rate the temperature tends to settle. From this it can be inferred that with higher feed rate and wheel speed, the prevailing wheel- work interface temperature could have changed the state of matrix aluminium to a plasticized/ molten state and thereby limiting further rise in the temperature monitored.

From the illustration on the surface finish in Fig.4, it can be observed that there is improvement in surface finish upto certain wheel speeds $(1400 \mathrm{~m} / \mathrm{min})$, beyond which deterioration sets in. Especially with increasing wheel speeds and higher table traverse rates the finish becomes poor, indicative of the drop in wheel performance (dulling of abrasives, loading due to thermal softening, etc) at higher grinding conditions. The illustration records grinding of $\mathrm{Al} / \mathrm{SiC}_{\mathrm{p}} \mathrm{MMC}$ with finer feed and moderate grinding speed for attaining good surface finish.

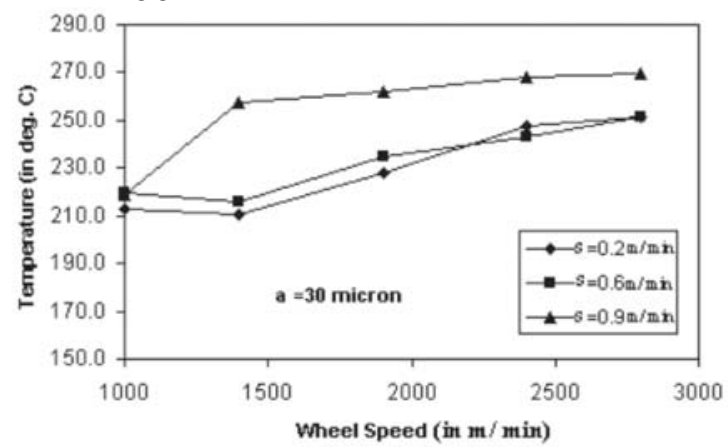

Fig.3 Parametric Influence on Grinding Temperature

It can be seen that above $1400 \mathrm{~m} / \mathrm{min}$ of wheel speed, a change in trend of variation of temperature occurs. Upto moderate feed, a rise in temperature occurs above $1400 \mathrm{~m} / \mathrm{min}$, while with high feed rate the temperature tends to settle. From this it can be inferred that with higher feed rate and wheel speed, the prevailing wheel- work interface temperature could have changed the state of matrix aluminium to a plasticized/ molten state and thereby limiting further rise in the temperature monitored. 


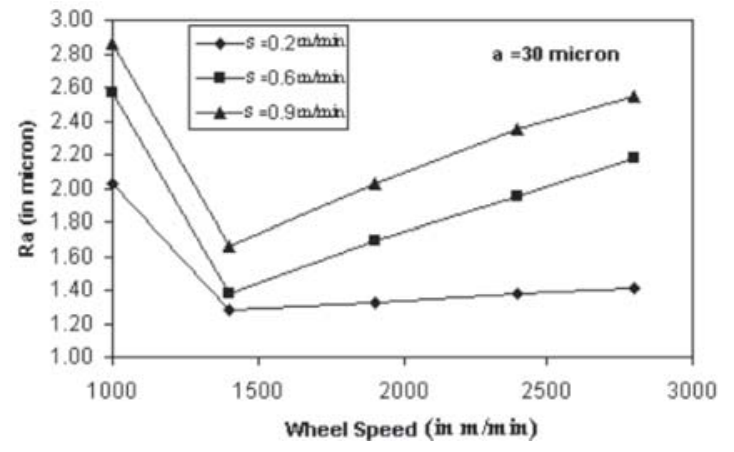

Fig.4 Typical Parametric Influence on Surface Finish

From the illustration on the surface finish in Fig.4, it can be observed that there is improvement in surface finish upto certain wheel speeds $(1400 \mathrm{~m} / \mathrm{min})$, beyond which deterioration sets in. Especially with increasing wheel speeds and higher table traverse rates the finish becomes poor, indicative of the drop in wheel performance (dulling of abrasives, loading due to thermal softening, etc) at higher grinding conditions. The illustration records grinding of $\mathrm{Al} / \mathrm{SiC}_{\mathrm{p}} \mathrm{MMC}$ with finer feed and moderate grinding speed for attaining good surface finish. Scanning electron micrograph of grinding $\mathrm{Al} / \mathrm{SiC}_{\mathrm{p}} \mathrm{MMC}$ at lower grinding condition is presented in Fig.5. The surface presents discrete streaks of grinding lay. Surface texture also presents flow of surface material, with a feathery texture.

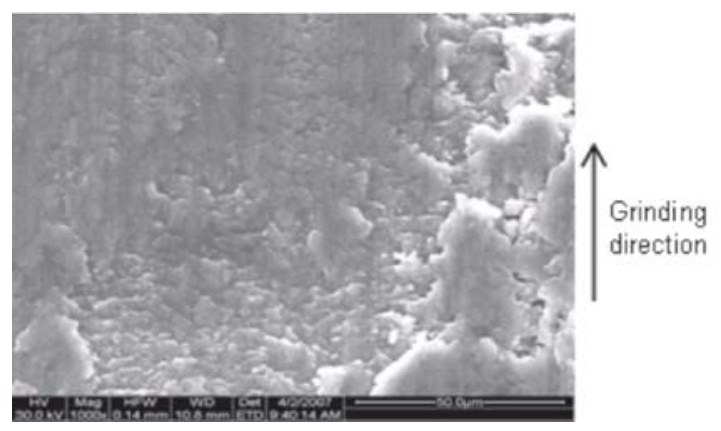

Fig.5 SEM of the Machined Surface (1000x) $(V=1000 \mathrm{~m} / \mathrm{min}, \mathrm{s}=0.2 \mathrm{~m} / \mathrm{min}, \mathrm{a}=10 \mu \mathrm{m})$

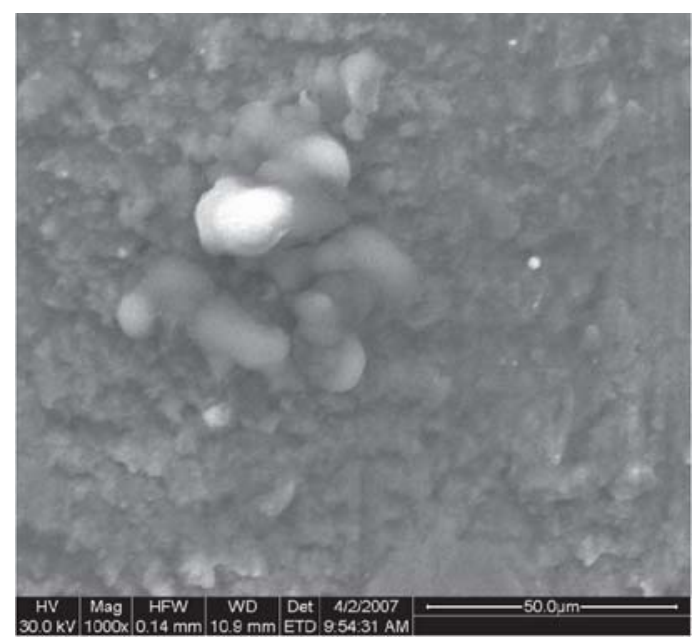

Fig.6 SEM of the Machined Surface (1000x) $(\mathrm{V}=1400 \mathrm{~m} / \mathrm{min}, \mathrm{s}=0.6 \mathrm{~m} / \mathrm{min}, \mathrm{a}=20 \mu \mathrm{m})$

Typical micrograph of $\mathrm{Al} / \mathrm{SiC}_{\mathrm{p}}$ surface ground with higher grinding condition is shown in Fig.6. Localized pull out of surface can be seen. The presence of molten solidified globules on the surface is indicative of higher order grinding temperature.

\section{A. Conclusions from the Case Study}

1. Good grinding of $\mathrm{Al} / \mathrm{SiC}$ with conventional $\mathrm{SiC}$ wheels can be done at lower wheel speeds, lower table traverse rates.

2. At higher grinding speeds, although the grinding force is less, the grinding temperature is relatively high, leading to possible thermal softening and sliding dominant grinding.

3. The deterioration in wheel performance is reflected in the recorded surface finish values, which could be confirmed from the surface texture observation also.

\section{CASE STUDY II - DRILLING CHARACTERISTICS OF THERMOPLASTICS COMPOSITES}

Development of composite materials, have highlighted the possibility of tailor made material composition to meet the complex requirements. Despite, their application is restricted to problems associated with the machinability. In order to evaluate the machinability of thermoplastics composites, drilling study was conducted was conducted on glass fiber reinforced polypropylene (GF/PP) composites and the data obtained are presented. 
Composites being non-homogeneous and anisotropic, their machining is quite different from that of homogeneous metallic materials. The material response is dependent on fiber and matrix properties, fiber orientation and interfacial bonding. The production of holes for structural applications in composite materials present altogether different problems from those encountered in metals. The process and material related problems encountered in drilling of fiber reinforced polymeric composites include: delamination, debonding, high cutting temperatures due to poor thermal conductivity of work material, matrix burning, abrasive wear of tool material and hazardous dust. Several operating variables are found to influence the nature and extent of the fracture involved during chip formation: geometry of tool, tool sharpness, cutting conditions and material characteristics. Hence, a complete understanding of the drilling characteristics of the composites is imperative to produce defect constrained holes at an economic scale.

Usually in drilling, machinability of a material can be evaluated in terms of drilling force, temperature, surface quality and tool wear. Drilling is a complex process involving combined action of axial (thrust) force and peripheral (torque) force. Mostly damage on the workpiece is inflicted by thrust force due to differential flexural properties of matrix and reinforcement fiber. Thrust force can be used as a process indicator for assessing the status of tool-work interface. Any change in the thrust force can be attributed to change in the status of cutting wedge either by deformation and other modes of tool wear or possible interactions between the tool and work material at the heat affected cutting zone.

\section{A. Parametric Influence of Cutting Force In Drilling Gf/pp Composites}

Selection of suitable cutting parameters is an important step in economic manufacture of components with specified dimensional tolerance. The quality of the machined parts is strongly dependent on drilling parameters. The change in cutting parameters will influence performance of the tool as well as the response of the work material. Different parameters/ performance of the tool as well as the response of the work material. Different parameters/ indicators are used to evaluate the performance of the tool and quality of the work material. Among them, components of cutting force are considered as the most important one. Thrust generated during drilling is identified as the parameter most responsible for the resultant hole quality. To minimize the thrust and associated defects various tool materials, such as HSS and hard tools such as K type cemented carbides were tried in the present study. In addition to the thrust force, moment of the cutting force or the torque also influences the quality of the hole produced. During the process of drilling, the sharp cutting edges over the periphery deform/ become blunt and produce friction by way of rubbing instead of cutting. This may be the cause for observed rise in the torque in conventional drilling. High speed steel (HSS), cemented carbides, coated carbides, and ceramics are traditionally used as cutting tool materials. Among these, HSS is being considered in the machining of composite materials, owing to its higher order fracture rupture strength (FRS) value.
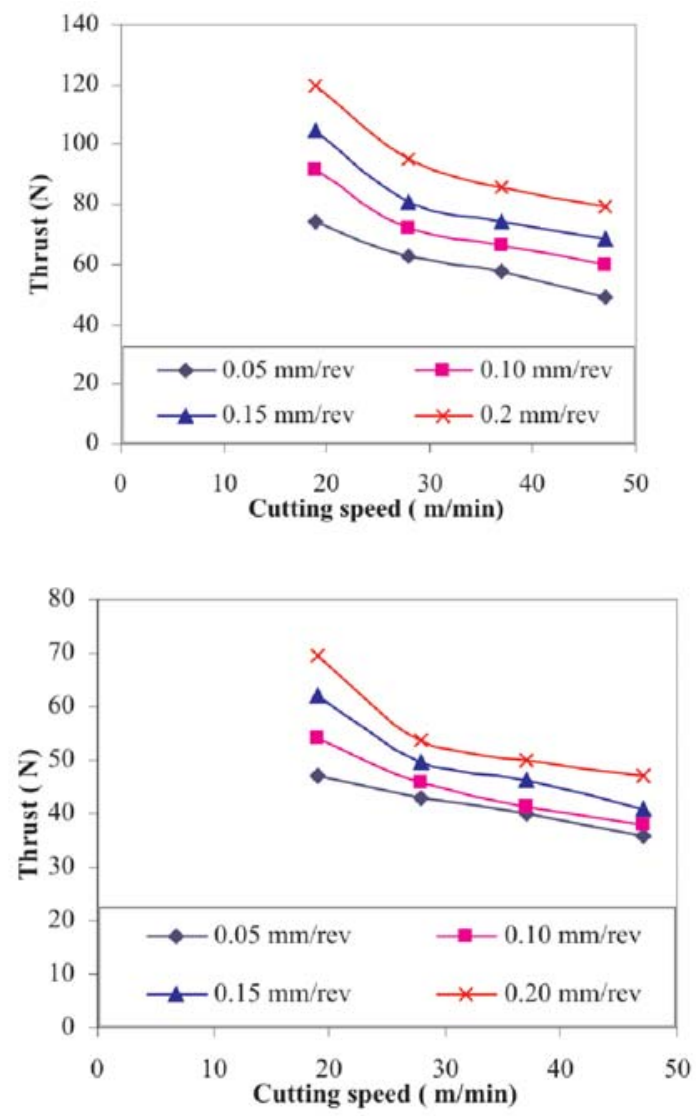

Fig. 7 Parametric Influence on Thrust Force For (a) Hss Drill (b) Tipped Carbide Drill

Typical parametric influence on thrust force during drilling of glass fiber reinforced polypropylene (GF/PP) composites using HSS, K-type tipped carbide and solid carbide drills are illustrated in figures 7 and 8 . The peak thrust monitored during a drilling operation is used to plot the typical variation with cutting conditions.

The observations clearly indicate a reduction in thrust and torque with drilling speed; relatively lower order thrust and torque can be seen with drilling speed of 47 $\mathrm{m} / \mathrm{min}$ and a feed of $0.05 \mathrm{~mm} / \mathrm{rev}$ for all the drills. And 
among the drills, solid carbide drills perform better by way of lower order thrust force.

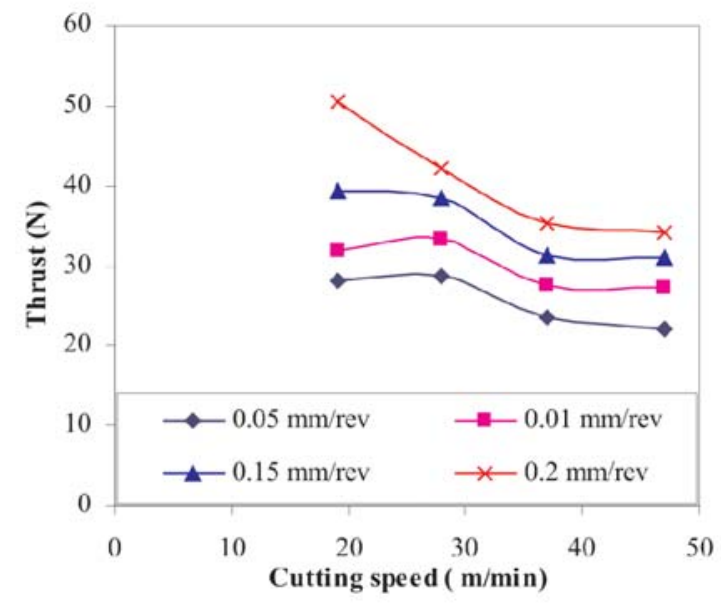

Fig. 8. Parametric Influence on Thrust Force For Solid Carbide Drill (gf/pp)

\section{B. Thrust force Observations Progressive Drilling of Gf/pp Composites}

The observations on thrust force indicate the best machining conditions of $47 \mathrm{~m} / \mathrm{min}$ cutting speed and 0.05 $\mathrm{mm} / \mathrm{rev}$ feed rate for all the tool materials. This condition has been used for progressive drilling of GF/PP composite laminates using HSS, tipped carbide and solid carbide drills. While drilling GF/PP with HSS tools the thrust was found to rise rapidly after 30 holes as illustrated in figure 9 . The lower order thermal resistivity of HSS tools and the abrasive fibers induce rapid wear of tool and consequent rapid rise in thrust. This can be attributed to the rapid rise in thrust. The performance of tipped carbide (TC) and solid carbide (SC) drills is better compared to HSS drills. The performance of solid carbide drill was found to be the best with lower order thrust, with only a marginal rise in thrust over large number of holes. This can be attributed to higher hot hardness, edge sharpness and form stability of the tool material at higher temperatures.

The diverse properties of the matrix and the reinforcement can cause force fluctuations of the cutting tool in machining the non-homogeneous material. These fluctuations will result in non-steady cutting associated with plowing and/or low cycle fatigue failures. Sudden chipping may occur in tools with lower fracture rupture strength. During drilling, the cutting edges and flank experience intensive adhesion/ sliding contact with either the chip or just machined work surface.

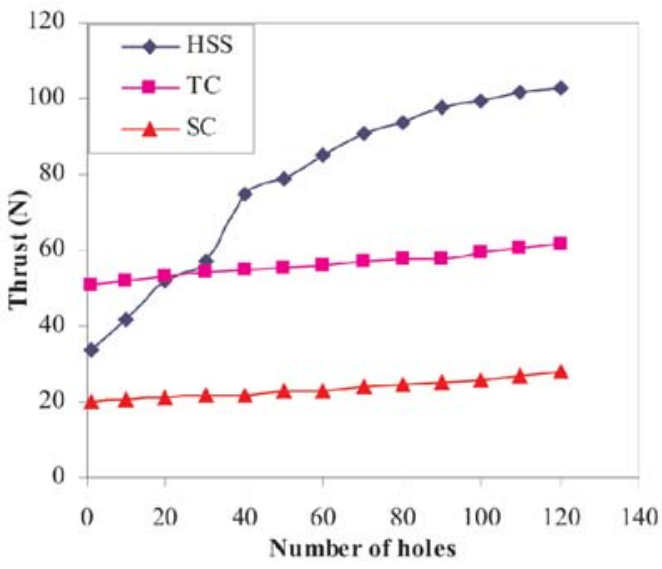

Fig. 9. Variation of Thrust with Progressive Drilling (gf/pp) Tool Wear - Observations

In addition to force fluctuation and intense contact, the cutting wedge experiences higher order temperature due to the poor thermal conductivity of polymeric composite and abrasion due to harder fibers. This results in different forms of wear depending on the conditions prevailing over the tool-work interface. Tool wear is the dominant phenomenon that affects wedge geometry and consequently the tool life. The most important type of wear in drilling is flank wear. Flank wear occurs because of the sliding contact with the workpiece. The increase in tool wear results in a change in material removal mechanism also. The variation of tool wear in progressive drilling is illustrated in figure 10. As in the case of cutting dynamics, solid carbide tools exhibit least wear during progressive drilling. With the increase in temperature during drilling, the thermoplastics melt at the interface and cover the fiber ends. The polypropylene film formed on the cutting wedges as illustrated in figure 11 acts as a barrier between the abrasive fibers and the tool resulting in lower tool wear as compared to thermoset machining. The adhesion of polymer on tool edges reduces the direct contact of sliding harder fibers on cutting wedges. This could be attributed to the controlled flank wear with marginal increase over large number of holes for machining of the GF/PP composites with tipped carbide and solid carbide tools. The accumulated heat in the HSS tools lead to plowing in GF/PP. Also, the higher strain-tofailure values of the thermoplastics result in plastic deformation and increased rubbing contact with fibers before shear by the cutting edges promoting higher order wear for HSS tools. 


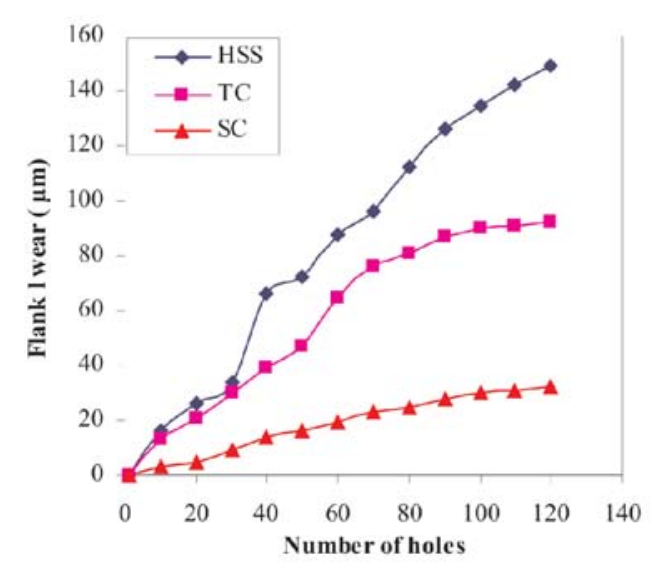

Fig.10. Variation of flank wear with progressive drilling (GF/PP)

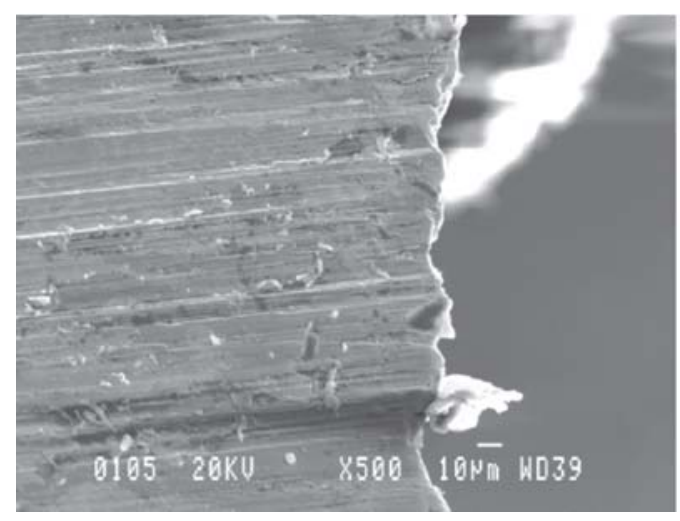

Fig. 11. SEM of HSS drill-flank (smoother surface with sheared polymer )

C. Response of the Workpiece With Respect To Hole Quality

Drilling introduces damages around the hole periphery in the form of delaminations or inaccuracies in the form of hole shrinkage, which may affect the integrity of the structure. Hole shrinkage due to elastic bending and tightening of the reinforcement fibers during machining and consequent relaxation is a common phenomenon in drilling of laminated polymeric composites. Thermoplastics expand or contract with application or removal of heat in the cutting zone. This nature of thermoplastics adds to hole shrinkage considerably. The observed variations in hole shrinkage for drilling GF/PP composites with HSS, tipped carbide and solid carbide drills is illustrated in Fig. 12. The hole shrinkage in the laminates varies in the same way as thrust and tool wear. The temperature at the cutting zone facilitates thermal softening of the polymer that covers the hole periphery similar to recast. This can minimise the fiber pullout/protrusion and result in better surface finish of the hola

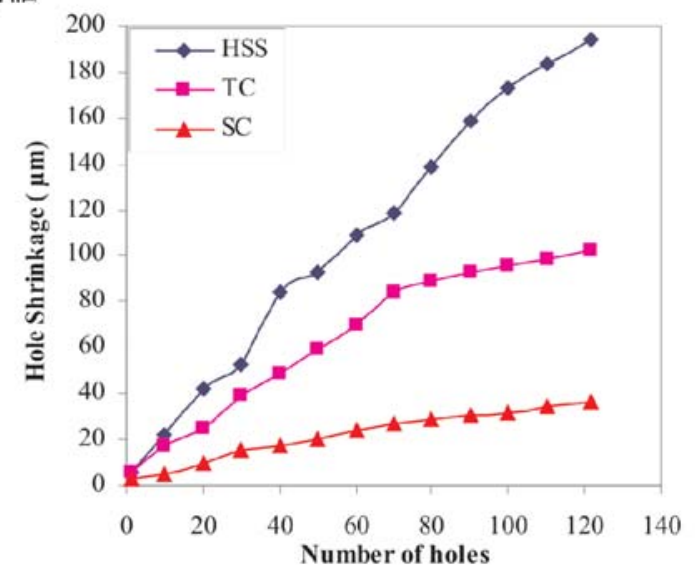

Fig. 12. Variation of hole shrinkage with progressive drilling (GF/PP)

\section{Conclusions from Case Study li}

The observations on thrust force indicate the best possible machining conditions of $47 \mathrm{~m} / \mathrm{min}$ cutting speed and $0.05 \mathrm{~mm} / \mathrm{rev}$ feed rate in drilling of GF/PP. Thermoplastics composites experience lower thrust forces, also temperature prevailing over the cutting zone favours formation of lubricating, ablative layer thereby minimising the tool wear. The soldd carbide tool outperforms in drilling. This could be due to considerable plastic deformation with much energy absorption by the thermoplastics composites which are prone to thermal softening.

The variation of thrust with number of holes in general shows progressive trend with a small rise over a long range. The chip morphology explains plastic deformation and shearing in machining. Long and curly chips were obtained for thermoplastics composites

\section{CASE STUDY III ULTRASONIC MACHINING STUDIES ON AL $\mathrm{O}_{3} / \mathrm{LAPO}_{4}$ COMPOSITES}

$\mathrm{Al}_{2} \mathrm{O}_{3} / \mathrm{LaPO}_{4}$ composites containing varying proportions of $\mathrm{LaPO}_{4}(0 \%, 30 \%, 50 \%$ and $100 \%$ by weight) were fabricated by conventional sintering method and subjected to conventional drilling. The specimens were characterized for studying the sinterability and machinabilty of the composites. It was observed that, with the addition of $\mathrm{LaPO}_{4}$, only a marginal change in machinability could be attained. Even specimens of $50 \% \quad \mathrm{LaPO}_{4}$ content could not be drilled by conventional 
methods, hence ultrasonic drilling has been resorted to.

\section{A. Material Removal Rate (MRR)}

Machinability of ceramic composites can be assessed in terms of material removal rate (MRR), tool wear and also other relative indirect indicators. Typical observed MRR as influenced by LaPO4 content is illustrated in figure13. It is seen that up to certain percentage content of LaPO4 a progressive rise in MRR occurs beyond which MRR tends to set in.. It is seen that the trend of variation in MRR with $\mathrm{LaPO} 4$ content, tends to change over with $30 \%$, marginally, and appreciably with $50 \%$. The observed rise in MRR (up to $30 \%$ LaPO4) could be attributed to increased order of sinterability and dispersion strengthening of the structure.

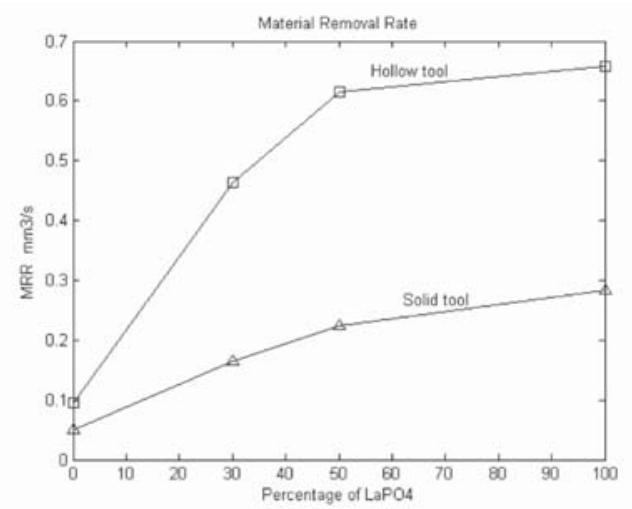

Fig. 13. Variation of MRR with Percentage of LaPO4

Ultrasonic drilling is associated with impingement of harder abrasives on the work piece at higher frequency $(=20 \mathrm{KHz})$; consequently the material is removed by matrix erosion due to momentum transfer and occasionally due to cavitation induced in the tool-work gap (due to high frequency oscillations of the tool). Hence hardness of the work material will be the prime factor in deciding the machinability. Normally higher the work piece hardness better will be the machining in terms of the geometrical accuracy of the hole drilled. However with increased fracture toughness $\left(k_{1 c}\right)$, ceramic composite can experience better machining by way of crack-free machining. Up to $30 \% \mathrm{LaPO} 4$ a progressive rise in machining rate can be seen, attributable to the critical value of LaPO4 content on structural compatibility. With $30 \%$ addition a rise in $\mathrm{E} / \mathrm{H}$ and $\mathrm{k}_{1 \mathrm{c}}$ (fracture toughness) occurs, making it susceptible to crack-free machining. i.e., MRR increases. It is to be noted that despite the reduction in hardness with $\mathrm{LaPO}_{4}$ content, only a marginal variation in MRR is seen above $50 \% \mathrm{LaPO} 4$ addition. The reduction in hardness and occurrence of defective microstructure dampens the hammering action and consequently the observed rise in MRR with $\mathrm{LaPO}_{4}$ addition could not be realized/sustained.

With hollow tool, appreciable enhancement in MRR can be seen. The continuous erosion facilitated by the central suction of the annular tool has resulted in improved abrasion action and hence improved MRR. During ultrasonic drilling, abrasive slurry is introduced between the work piece and an oscillating tool. The tool material is usually softer steel. The abrasive slurry falls on the oscillating tool with the consequent hammering of the abrasive on the work piece. The tool can be solid or annular section. With the solid tool as the tool penetrates in to the work piece, the effective end erosion drops down. With hollow tool, the abrasive flow is maintained well (associated with central suction) enhancing the material removal rate appreciably as seen in the illustration.

\section{B. Conventional Machining of $\mathrm{Al}_{2} \mathrm{O}_{3} / \mathrm{lapo}_{4}$ Composites Fabricated By New Method-drilling Observations}

Since the specimens fabricated by conventional sintering method could not be drilled by conventional drilling, the specimens were prepared by liquid infiltration method and and tried for conventional drilling. It was observed that (50:50) $\mathrm{Al}_{2} \mathrm{O}_{3} / \mathrm{LaPO}_{4}$ could be easily drilled. Conventional drilling of 50:50 composite has been carried out on an optical co-ordinate type boring machine with spindle speed of $1200 \mathrm{~m} / \mathrm{min}$ and a feed of $0.01 \mathrm{~mm} / \mathrm{rev}$. Typical configurations of drilled holes, both at entry and exit side are illustrated in figures 14 and 15 respectively. Geometrical accuracy could be maintained but for the exit fluffing. This could be controlled by reducing the feed rate. Typical monitored variation of thrust and torque during drilling of the $\mathrm{Al}_{2} \mathrm{O}_{3} / \mathrm{LaPO}_{4}$ ceramic composite is illustrated in Figures 16 and 17 respectively. It is seen that, as the drill point enters, the thrust force increases, and becomes steady with full engagement of the tool.

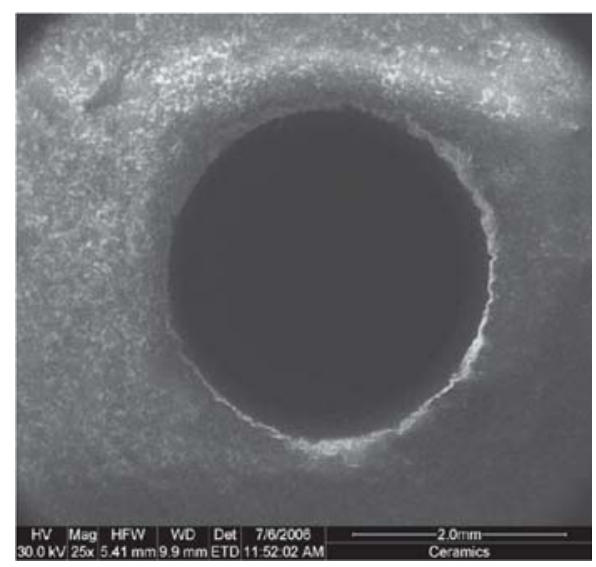

Fig.14 Configuration of Drilled Hole At Inlet Side 


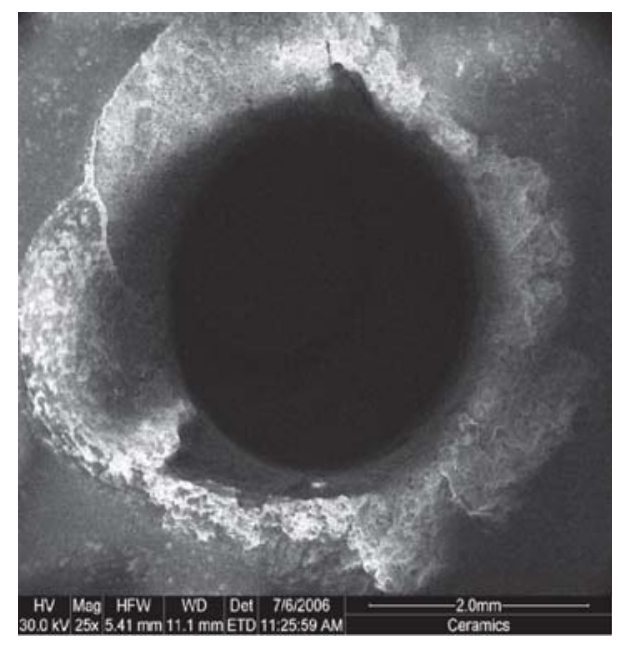

Fig.15 Configuration of Drilled Hole At Exit Side

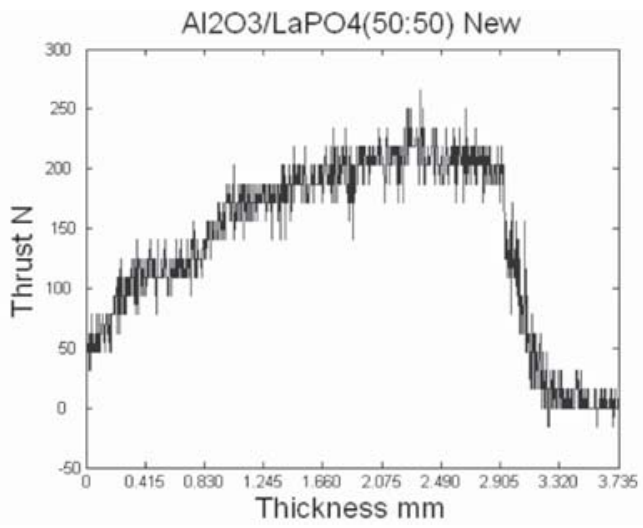

Fig.16 Variation of Thrust During Drilling

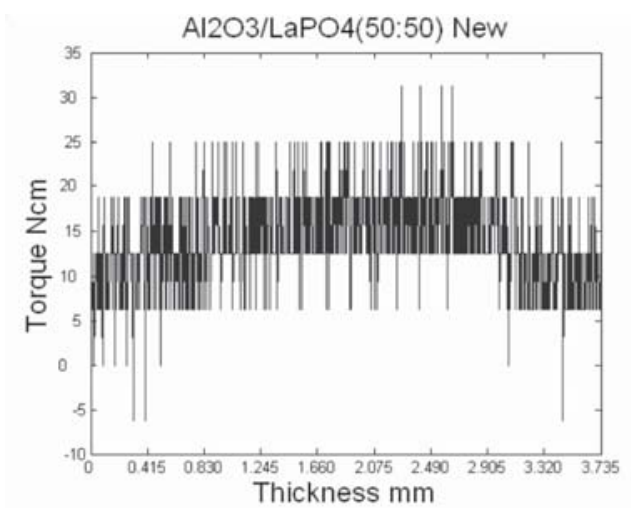

Fig.17 Variation of Torque During Drilling
Barring the entry/exit region, the torque monitored, is more or less steady, i.e., peripheral cutting is steady.

\section{Conclusions from Case Study iii}

Ultrasonic drilling of Al2O3/LaPO4 composite indicates good machinability in the 70:30 proportion and also, with hollow tool, enhanced machinability can be obtained. In conventional drilling with 50:50 composites prepared through the liquid infiltration technique geometrical accuracy could be obtained, but for exit fluffing.

\section{ACKNOWLODGEMENT}

This presentation is based on the work carried out by the research scholars R.Varatharajan, Anand Ronald and Abdul Majeed working with the author.

\section{REFERENCES}

[1] "haowei "hong and Nguyen Phu Hung (2002), "Grinding of Alumina / Aluminium Composites", Journal of Material Processing Technology 123 pp.13-17.

[2] Gul Tosun, Mehtap Muratoglu (2004), "The drilling of an Al/ SiC metal matrix composites: Part-II: Workpiece surface integrity", Composites Science and Technology, Volume 64, Issues 10-11, pp. 14131418.

[3] Sundaram. S, N.Anantharaman (2001), "Temperature and Wheel loading in grinding of Al/ SiCp composites"AIMS 2001, pp.140-149.

[4] Cheung. C.F, K.C. Chan, S. To, W.B. Lee (2002), "Effect of reinforcement on surface finish in ultraprecision diamond turning of $\mathrm{Al} / \mathrm{SiC}$ metal matrix composites", Scripta Mater. 47/2, pp.7782.

[5] R.Varatharajan (2007) "Processing, Characterization and Drilling of Fiber Reinforced Thermoplastics Composites" Ph.D thesis, IIT Madras. 